\title{
Epidemiologic study of urolithiasis in seven countries of South-Eastern Europe: S.E.G.U.R. 1 study
}

\author{
Andreas Karagiannis ${ }^{1}$, Andreas Skolarikos ${ }^{1}$, Emanuel Alexandrescu ${ }^{2}$, Dragoslav Basic ${ }^{3}$, \\ Petrisor Geavlete ${ }^{2}$, Alessandro Maletta ${ }^{4}$, A.Yaser Muslumanoglu ${ }^{5}$, Athanasios Papatsoris ${ }^{1}$, \\ Kremena Petkova ${ }^{6}$, Skender Saidi ${ }^{7}$, Aleksandar Skakic ${ }^{3}$, Iliya Saltirov ${ }^{6}$, Kemal Sarica ${ }^{8}$, \\ Sotir Stavridis ${ }^{7}$, Omer Yilmaz ${ }^{9}$, Alberto Trinchieri ${ }^{4}$ \\ ${ }^{1} 2^{\text {nd }}$ Department of Urology, University of Athens, Sismanoglio Hospital, Greece; \\ ${ }^{2}$ Urological Department, Saint John Emergency Clinical Hospital, Romania; \\ ${ }^{3}$ Urological Clinic, Clinical Center Nis, Serbia; \\ ${ }^{4}$ Ospedale A.Manzoni Urology Department, Lecco, Italy; \\ ${ }^{5}$ Department of Urology, Bagcilar Training and Research Hospital, Istanbul, Turkey; \\ ${ }^{6}$ Department of Urology and Nephrology, Military Medical Academy, Sofia, Bulgaria; \\ ${ }^{7}$ Urology Department, University Clinical Centre "Mother Theresa" Skopje, FYR Macedonia; \\ ${ }^{8}$ Dr. Lutfi KIRDAR Kartal Research and Training Hospital, Istanbul, Turkey; \\ ${ }^{9}$ Department of Urology, GATA Haydarpasa Research and Teaching Hospital, Istanbul, Turkey.
}

\begin{abstract}
Summary Objective: To investigate some epidemiologEastern European area.

Materials and methods: From September 2015 to December 2015, 538 consecutive patients were treated and evaluated for reno-ureteral stones in eight departments in Bulgaria, Greece, Italy, FYR Macedonia, Romania, Serbia and Turkey.

Results: The age of onset was lower in Turkey and higher in Italy. The rate of recurrent patients was higher in Romania and Serbia, while first renal stone formers were more frequent in Italy. The previous history of kidney stones, the characteristics of the stones and the dietary habits of the patients were different in different countries. In Bulgaria, Greece and Romania larger calculi from recurrent patients were more frequent. In Italy and Turkey smaller calculi from first renal stone formers were more frequent.

Conclusions: The previous history of kidney stones, the characteristics of the stones and the dietary habits of the patients were different in different countries. A common dietary pattern associated with the formation of kidney stones was not observed, but each country showed different risk factors.
\end{abstract}

KEY WORDS: Urolithiasis; Epidemiology; Diet.

Submitted 7 May 2017; Accepted 15 July 2017

\begin{abstract}
INTRODUCTION
The epidemiology of urolithiasis has been frequently correlated with geography, climate and culture (1).

The area of South Eastern Europe is relatively homogeneous in topography, climate and eating habits. In some countries of this area the prevalence of urolithiasis was assessed according to population-based studies. In Italy, the prevalence was estimated at $6.8 \%$ (males) and $4.9 \%$ (females) in 1986 and 10.1\% (M) and 5.8\% (F) in 1998 (2), in Turkey it amounted to $14.8 \%$ in 1989 (3) and in Greece 15\% in 2006 (4). Limited information is available about renal stone prevalence in Bulgaria, FYR Macedonia,
\end{abstract}

Romania and Serbia (5). These prevalence rates are higher than those reported in other regions of Europe such as Germany (4.7\%) (6) and the United Kingdom (3.5\%) (7) and can be explained by the warmer climate. On the contrary, the South-East European area is characterized by the consumption of the Mediterranean diet, that has long been associated with lower incidence of cardiovascular disease and cancer $(8,9)$. Some components of the Mediterranean diet as vegetables, fruits, potatoes, legumes and dairy products may be potentially favorable for the prevention of kidney stones.

Aim of this study was to evaluate several epidemiological features and dietary habits, in patients with renal stones treated in seven countries of the South-Eastern Europe.

\section{MATERIALS AND METHODS}

From September 2015 to December 2015, 538 consecutive patients were treated for reno-ureteral stones in eight urological departments in Bulgaria, Greece, Italy, FYR Macedonia, Romania, Serbia and Turkey. The patients were evaluated on the basis of a questionnaire posted on www.segurgroup.eu website. The questionnaire investigated extensively patient characteristics, including age, gender, weight, height, body mass index (BMI), working and sporting activity, bowel habits, urinary volume, presence of urological diseases or medical diseases related to stone formation, previous urinary tract infection, renal function, fluid intake and dietary habits, stone history and stone characteristics (size, location, composition, side and treatment modality).

Working activity was scored as light, heavy and very heavy and sporting activity as light, intermediate, high and professional; intake of food categories (pasta/rice/pizza, meat/poultry/fish, cheese, vegetables, fruit) as never or rarely, often, daily; milk/yogurt intake as $\mathrm{n}^{\circ}$ cups/day; bread intake $n^{\circ}$ of loafs/slices/day. Working activity and 
dietary assessment was carried out by the Urologist which interviewed the patients by recall method.

The results of the questionnaire were compared according to the country of the evaluated subjects.

Stone analysis was performed on the 360 out of 538 patients (the ESWL patients didn't have stone analysis) and was mainly chemical analysis (82\%) whereas the rest by diffractometry.

\section{Statistical analysis}

Normality was tested using the Shapiro-Wilk test. Normally distributed data were presented as mean (S.D.) as for not normally distributed data median and interquartile range (IQR) were used. Comparisons between countries for normally distributed data was conducted using ANOVA. Comparisons for not normally distributed data was performed using Kruskal-Wallis test. Fisher's exact test was applied for comparisons with categorical data. Dunn's multiple comparisons test was applied after a significant Kruskal-Wallis or Fishers exact test. Sidak correction was used for multiple comparisons between countries. Analysis was conducted using StataCorp. 2013. Stata Statistical Software: Release 13. College Station, TX: StataCorp LP.

\section{RESULTS}

A total of 538 patients were enrolled of whom 124 from Bulgaria, 17 from FYR Macedonia, 50 from Greece, 65 from Italy, 122 from Romania, 55 from Serbia and 106 from Turkey.

\section{Gender and age}

In total the male to female ratio (M/F) was 1.07 with a 0.82 in Bulgaria, 1.42 in FYR Macedonia, 1.77 in Greece, 1.5 in Italy, 1.03 in Romania, 0.62 in Serbia and 1.23 in Turkey. Difference of distribution of the disease by gender for different countries was not significant ( $\mathrm{p}=0.065)$.

Age at stone onset was 39.9+/-16.2 in the total population with significant differences between different countries $(p<0.001)$. In Turkey it was significantly lower than in Greece, Italy, Romania and Serbia whereas in Bulgaria and FYR Macedonia it was significantly lower than in Greece and Italy (Table 1).

\section{Height, weight and BMI}

There were no statistically significant differences between patients from different countries for height, weight and BMI (Table 1).

There was a statistically significant difference by gender for weight $(\mathrm{p}<0.001)$, height $(\mathrm{p}<0.001)$ and BMI $(\mathrm{p}<$ 0.001 ). No statistical significant differences of weight $($ ANOVA F-test $=0.185)$ and BMI (ANOVA F-test $=$ 0.185 ) were observed in women by different countries. Height of women by different countries was significantly different (ANOVA F-test < 0.001) with Serbian female patients taller than female patients of other countries (ANOVA F-test < 0.05) except patients from FYR Macedonia.

Statistical differences of height, weight and BMI (ANOVA F-test $<0.001$ ) were observed in men from different countries.
Male Turkish patients were shorter than patients from all other countries but male patients from Italy (ANOVA F-test $<0.05$ ).

Male Bulgarian patients were significantly heavier than male patients from Italy, Turkey and Romania (ANOVA F-test $<0.05)$ and showed higher BMI scores than male patients from Serbia and Romania. Also male patients from Turkey had higher BMI scores than patients from Romania (ANOVA F-test < 0.05).

\section{Urological and medical diseases}

Urological anomalies were observed in 63/538. The more common were urethral stenosis $(5.39 \%)$, ureteral stenosis (2.6\%), ureteropelvic junction (UPJ) stenosis (2.33\%) and horseshoe kidney (1.49\%).

Medical diseases related to renal stone formation were observed in 118/538. The more frequent were bone disease $(6.51 \%)$, peptic ulcer $(6.13 \%)$, gout $(3.35 \%)$, hyperthyroidism (2.24\%), diabetes mellitus (2.23\%) hyperparathyroidism (1.35\%).

Statistically significant different rates of urological diseases and of medical diseases related to stone formation were observed for patients from different countries (chi2 test $p<0.001$ and $p=0.016$ ) with the highest rate of urological diseases observed in Romania (73.7\%) and. FYR Macedonia (88.2\%) and the highest rate of medical diseases in Turkey (40\%).

\section{Working and sporting activity}

Statistically significant difference was observed for working and sporting activity between patients from different countries $(p=0.001$ and $p=0.005)($ Table 1$)$.

Bulgarians patients had heavy working activity (47.6\%) with respect to patients from other countries (20$32.8 \%)$. Heavy or intermediate sporting activity was more frequent in patients from Bulgaria and Serbia (51.8\% and $50 \%$ ) with respect to other countries (14\%$43.8 \%)$.

\section{Dietary habit}

Intakes of pasta, meat, cheese, vegetables, fruit, milk and bread were significantly different in different countries (ANOVA F-test < 0.001) (Table 2).

Patients from Italy tended to consume more pasta products (pasta/rice/pizza) in comparison with patients from all other countries ( $p<0.05$ in all comparisons) except patients from FYR Macedonia. Patients from Romania tended to consume less pasta products in comparison with patients from Greece, FYR Macedonia and Turkey (p $<0.05$ in all comparisons) and patients from Bulgaria tended to consume less pasta in comparison with patients from all other countries $(\mathrm{p}<0.05)$.

Patients from Romania tended to consume less vegetables in comparison with patients from all other countries $(p<0.05)$ and those from Serbia more vegetables than those from Turkey $(\mathrm{p}<0.05)$.

Patients from Italy and FYR Macedonia tended to consume more fruits in comparison with patients from all other countries $(\mathrm{p}<0.05)$.

Patients from Romania tended to consume more bread in comparison with patients from all other countries except patients from FYR Macedonia $(\mathrm{p}<0.05)$ and patients 
Table 1.

Demographic and clinical data of patients by different countries.

\begin{tabular}{|c|c|c|c|c|c|c|c|c|c|}
\hline & $\begin{array}{l}\text { Bulgaria } \\
(n=124)\end{array}$ & $\begin{array}{l}\text { FYR Macedonia } \\
\qquad(n=17)\end{array}$ & $\begin{array}{l}\text { Greece } \\
(n=50)\end{array}$ & $\begin{array}{c}\text { Italy } \\
(n=65)\end{array}$ & $\begin{array}{l}\text { Romania } \\
(n=122)\end{array}$ & $\begin{array}{l}\text { Serbia } \\
(n=55)\end{array}$ & $\begin{array}{c}\text { Turkey } \\
(n=106)\end{array}$ & $\begin{array}{c}\text { Overall } \\
(n=538)\end{array}$ & $P$ value \\
\hline Gender $\dagger$ & & & & & & & & & 0.065 \\
\hline Female & $54.8 \%$ & $41.2 \%$ & $36.0 \%$ & $40.0 \%$ & $49.2 \%$ & $61.8 \%$ & $44.8 \%$ & $48.3 \%$ & \\
\hline Male & $45.2 \%$ & $58.8 \%$ & $64.0 \%$ & $60.0 \%$ & $50.8 \%$ & $38.2 \%$ & $55.2 \%$ & $51.7 \%$ & \\
\hline BMI $\neq$ & $27.4(5.52)$ & $25.1(2.65)$ & $26.9(3.62)$ & $26.0(4.31)$ & $26.7(6.07)$ & $26.7(8.43)$ & $26.5(4.93)$ & $26.7(5.57)$ & 0.022 \\
\hline Age $\rceil^{\prime}$ & $52.5(13.67)$ & $49.9(15.93)$ & $57.1(13.70)$ & $50.3(15.23)$ & $44.7(15.23)$ & $50.3(13.35)$ & 43.3(14.88) & $48.8(15.10)$ & 0.593 \\
\hline Age onset $\emptyset^{\prime}$ & $37.1(17.43)$ & $36.1(12.30)$ & $47.3(17.82)$ & $44.9(17.86)$ & $42.5(16.32)$ & $42.4(10.86)$ & $33.8(12.52)$ & $39.9(16.18)$ & $<0.001$ \\
\hline First time former & $33.9 \%(n=42)$ & $35.3 \%(n=6)$ & $34.0 \%(n=17)$ & $56.9 \%(n=37)$ & $14.7 \%(n=104)$ & $1.8 \%(n=1)$ & $37.1 \%(n=39)$ & $45.7 \%(n=246)$ & ) - \\
\hline Recurrence $£$ & $\begin{array}{c}0.16 \\
{[0.09-0.40]}\end{array}$ & $\begin{array}{c}0.17 \\
{[0.10-0.40]}\end{array}$ & $\begin{array}{c}0.37 \\
{[0.15-0.60]}\end{array}$ & $\begin{array}{c}0.20 \\
{[0.13-0.48]}\end{array}$ & $\begin{array}{c}1.0 \\
{[0.25-1.0]}\end{array}$ & $\begin{array}{c}0.71 \\
{[0.50-1.0]}\end{array}$ & $\begin{array}{c}0.29 \\
{[0.14-0.60]}\end{array}$ & $\begin{array}{c}0.37 \\
{[0.14-0.84]}\end{array}$ & $<0.001$ \\
\hline$\overline{\text { Working activity } \dagger}$ & & & & & & & & & 0.001 \\
\hline Light & $52.4 \%$ & $76.5 \%$ & $72.0 \%$ & $67.2 \%$ & $75.2 \%$ & $80.0 \%$ & $72.6 \%$ & $68.7 \%$ & \\
\hline Heavy & $47.6 \%$ & $23.5 \%$ & $28.0 \%$ & $32.8 \%$ & $24.8 \%$ & $20.0 \%$ & $27.4 \%$ & $31.3 \%$ & \\
\hline Sports $\dagger$ & & & & & & & & & 0.005 \\
\hline Light & $48.2 \%$ & $75.0 \%$ & $86.0 \%$ & $58.1 \%$ & $55.7 \%$ & $50.0 \%$ & $66.1 \%$ & $62.1 \%$ & \\
\hline Intermediate & $48.2 \%$ & $25.0 \%$ & $12.0 \%$ & $32.3 \%$ & $39.3 \%$ & $39.3 \%$ & $23.7 \%$ & $31.9 \%$ & \\
\hline Heavy & $3.6 \%$ & $0.0 \%$ & $2 \%$ & $9.7 \%$ & $4.9 \%$ & $10.7 \%$ & $10.2 \%$ & $6.0 \%$ & \\
\hline Bowel $\dagger$ & & & & & & & & & 0.002 \\
\hline Regular & $79.0 \%$ & $52.9 \%$ & $82.0 \%$ & $79.0 \%$ & $69.2 \%$ & $78.4 \%$ & $58.0 \%$ & $72.1 \%$ & \\
\hline Non - regular & $21.0 \%$ & $47.1 \%$ & $18.0 \%$ & $21.0 \%$ & $30.8 \%$ & $21.6 \%$ & $42.0 \%$ & $27.9 \%$ & \\
\hline Renal insufficiency $\dagger$ & & & & & & & & & $<0.001$ \\
\hline$<1.2$ & $79.0 \%$ & $70.6 \%$ & $84.0 \%$ & $76.7 \%$ & $52.7 \%$ & $74.6 \%$ & $89.6 \%$ & $74.7 \%$ & \\
\hline$>=1.2$ & $21.0 \%$ & $29.4 \%$ & $16.0 \%$ & $23.3 \%$ & $47.3 \%$ & $25.4 \%$ & $10.4 \%$ & $25.3 \%$ & \\
\hline \multicolumn{10}{|c|}{$\begin{array}{l}\text { † Fisher's exact test. } \\
\text { ‡ Data presented as Mean (S.D.). One-way ANOVA conducted for comparisons between nations. } \\
£ \text { Data presented as Median [IQR]. Dunn test (median test) conducted for multiple comparisons. } \\
\star I Q R=\text { Interquartile Range. }\end{array}$} \\
\hline
\end{tabular}

Table 2.

Dietary patterns of patients by different countries.

\begin{tabular}{|c|c|c|c|c|c|c|c|c|c|}
\hline & Bulgaria & FYR Macedonia & Greece & Italy & Romania & Serbia & Turkey & Overall & $P$ value \\
\hline Pasta/rice/pizza/etc. $\dagger$ & & & & & & & & & $<0.001$ \\
\hline Never/rarely & $81.5 \%$ & $23.5 \%$ & $8.0 \%$ & $8.1 \%$ & $52.5 \%$ & $25.4 \%$ & $30.4 \%$ & $41.9 \%$ & \\
\hline Often & $17.7 \%$ & $17.7 \%$ & $68.0 \%$ & $17.7 \%$ & $43.4 \%$ & $58.2 \%$ & $24.5 \%$ & $33.8 \%$ & \\
\hline Daily & $0.8 \%$ & $58.8 \%$ & $24.0 \%$ & $74.2 \%$ & $4.1 \%$ & $16.4 \%$ & $45.1 \%$ & $24.3 \%$ & \\
\hline Meat (any type) $\dagger$ & & & & & & & & & $<0.001$ \\
\hline Never/rarely & $13.7 \%$ & $29.4 \%$ & $6.0 \%$ & $3.2 \%$ & $3.3 \%$ & $0.0 \%$ & $19.6 \%$ & $9.6 \%$ & \\
\hline Often & $56.5 \%$ & $23.5 \%$ & $72.0 \%$ & $24.2 \%$ & $82.6 \%$ & $80.0 \%$ & $56.9 \%$ & $61.6 \%$ & \\
\hline Daily & $29.8 \%$ & $47.1 \%$ & $22.0 \%$ & $72.6 \%$ & $14.1 \%$ & $20.0 \%$ & $23.5 \%$ & $28.8 \%$ & \\
\hline Cheese $\dagger$ & & & & & & & & & $<0.001$ \\
\hline Never/rarely & $11.3 \%$ & $11.8 \%$ & $6.1 \%$ & $29.0 \%$ & $4.1 \%$ & $50.9 \%$ & $18.6 \%$ & $16.8 \%$ & \\
\hline Often & $55.6 \%$ & $23.5 \%$ & $53.1 \%$ & $35.5 \%$ & $87.6 \%$ & $47.3 \%$ & $34.3 \%$ & $54.3 \%$ & \\
\hline Daily & $33.1 \%$ & $64.7 \%$ & $40.8 \%$ & $35.5 \%$ & $8.3 \%$ & $1.8 \%$ & $47.1 \%$ & $28.9 \%$ & \\
\hline Vegetables $\dagger$ & & & & & & & & & $<0.001$ \\
\hline Never/rarely & $1.6 \%$ & $0.0 \%$ & $10.0 \%$ & $21.0 \%$ & $0.8 \%$ & $0.0 \%$ & $12.0 \%$ & $6.3 \%$ & \\
\hline Often & $44.7 \%$ & $11.8 \%$ & $36.0 \%$ & $19.3 \%$ & $81.7 \%$ & $23.6 \%$ & $32.0 \%$ & $43.6 \%$ & \\
\hline Daily & $53.7 \%$ & $88.2 \%$ & $54.0 \%$ & $59.7 \%$ & $17.5 \%$ & $76.4 \%$ & $56.0 \%$ & $50.1 \%$ & \\
\hline Fruits $\dagger$ & & & & & & & & & $<0.001$ \\
\hline Never/rarely & $19.4 \%$ & $5.9 \%$ & $36.0 \%$ & $19.4 \%$ & $16.5 \%$ & $9.1 \%$ & $29.4 \%$ & $20.7 \%$ & \\
\hline Often & $55.6 \%$ & $23.5 \%$ & $30.0 \%$ & $3.2 \%$ & $68.6 \%$ & $81.8 \%$ & $34.3 \%$ & $47.7 \%$ & \\
\hline Daily & $25.0 \%$ & $70.6 \%$ & $34.0 \%$ & $77.4 \%$ & $14.9 \%$ & $9.1 \%$ & $36.3 \%$ & $31.6 \%$ & \\
\hline Milk $\dagger$ & & & & & & & & & $<0.001$ \\
\hline Never & $9.7 \%$ & $0.0 \%$ & $68.0 \%$ & $41.0 \%$ & $29.7 \%$ & $0.0 \%$ & $19.6 \%$ & $24.0 \%$ & \\
\hline 1-2/day & $80.6 \%$ & $87.5 \%$ & $30.0 \%$ & $59.0 \%$ & $64.4 \%$ & $63.0 \%$ & $51.0 \%$ & $62.3 \%$ & \\
\hline 3 or more/day & $9.7 \%$ & $12.5 \%$ & $2.0 \%$ & $0.0 \%$ & $5.9 \%$ & $37.0 \%$ & $29.4 \%$ & $13.7 \%$ & \\
\hline Bread $\dagger$ & & & & & & & & & $<0.001$ \\
\hline Never & $4.0 \%$ & $0.0 \%$ & $6.0 \%$ & $16.1 \%$ & $0.0 \%$ & $0.0 \%$ & $6.9 \%$ & $4.7 \%$ & \\
\hline 1-2/day & $42.8 \%$ & $58.8 \%$ & $50.0 \%$ & $79.0 \%$ & $25.4 \%$ & $63.0 \%$ & $47.0 \%$ & $47.1 \%$ & \\
\hline 3 or more/day & $53.2 \%$ & $41.2 \%$ & $44.0 \%$ & $4.9 \%$ & $74.6 \%$ & $37.0 \%$ & $46.1 \%$ & $48.2 \%$ & \\
\hline
\end{tabular}


from Italy less bread in comparison with patients from all other countries $(\mathrm{p}<0.05)$.

Patients from Serbia tended to consume more milk than patients from all other countries except FYR Macedonia and Turkey $(\mathrm{p}<0.05)$ and patients from Bulgaria and Turkey tended to consume more milk in comparison with patients from Greece, Italy and Romania ( $\mathrm{p}<0.05$ ). Patients from Italy tended to consume more meat products in comparison with patients from all other countries ( $p<0.05$ in all comparison). Patients from Serbia tended to consume more cheese product in comparison with patients from all other countries ( $\mathrm{p}<0.05$ in all comparisons) and patients from FYR Macedonia to consume more cheese products than those from Romania $(\mathrm{p}<0.05)$.

\section{Discussion}

Several studies have shown that urinary calculi tend to be more frequent in men, although infection stones were often more frequently reported in women $(10,11)$. Our study confirmed that nephrolithiasis is more frequent in men, although in Bulgaria and Serbia we observed more stones in women.

This can be explained by the higher rate of infection stones in Bulgarian patients with respect to patients from other countries. The rate of infection stones in FYR Macedonia was much higher but the number of patients from this country was very low. On the other hand, stones were more frequent in females also in Serbia, but information of stone composition from this country was limited.

Age at stone onset was lower in Turkey and Bulgaria and higher in Italy.

Stone onset of hereditary stones, such as cystine, tend to be low whereas uric acid stone formation is typical of older patients. In our series, cystine stones were more frequent in FYR Macedonia and, at a lesser extent, in Turkey and Bulgaria and uric acid stones were less frequent in FYR Macedonia and Turkey than in other countries.

A higher rate of hereditary stones together with a lower rate of uric acid stones could be an explanation of the lower age at stone onset in Turkey. In Italy the higher age at stone onset could be related to the prevalence of first renal stone formers that are characterized by a later onset of stone disease (12).

The dietary pattern correlated with renal stone formation is complex, because the risk of renal calcium stone formation may depend on a reduced intake of fluids, an insufficient calcium intake, an increased intake of protein and sodium and a reduced intake of potassium (13). Consequently, the formation of calcium stones can be favored by reduced fluid intake, excessive consumption of meat, a low intake of milk and dairy products and insufficient consumption of vegetables. Not necessarily all of these factors must coexist simultaneously, as it is the sum of the effects of each of them to determine the risk of kidney stones (14).

For this reason, it is not surprising to observe different dietary patterns in patients living in different countries where the diet may be different due to geographical, cultural and socioeconomic factors.

Our study was not specifically designed to evaluate stone prevalence in different countries or the potential role of diet in renal stone formation because of the absence of control subjects, but it interestingly demonstrated that renal stone patients from different countries show different dietary patterns.

In Italy, socioeconomic changes of the past 50 years have resulted in a progressive abandonment of the traditional Mediterranean diet.

Today, the daily consumption of pasta and rice remained frequent, but the daily meat consumption increased ( 1 or more servings per day in $75 \%$ of cases), while the consumption of cheese and milk is relatively infrequent (never or rarely in 29 and $41 \%$ ).

The dietary pattern of stone patients in Bulgaria, Greece and Turkey tends to be similar with a moderate consumption of meat (1 or more servings a day only in $29.8 \%, 22 \%$ and $23.5 \%$ ) and a decent cheese consumption (never or rarely in $11.3 \%, 6.1 \%$ and $18.6 \%$ ). However, the consumption of vegetables and fruit in these countries is relatively low ( 1 or more servings of vegetables and fruit per day of $53.7+25 \%, 54+34 \%$ and $56+36.3 \%$, respectively) and milk consumption in Greece is low (never or rarely in the 68\%).

In Romania and Serbia, the consumption of meat and cheese is high (often in $82.6 \%+87.6 \%$ and $80 \%+$ $47.3 \%$ ), but the consumption of vegetables and fruits is very low in Romania (1 or more servings a day in 17.5 and $14.9 \%$ ) and that of fruit is low in Serbia (1 or more servings per day in 9.1\%); also the consumption of milk is reduced in Romania (never in 29.7\%).

\section{Conclusions}

In conclusion different dietary patterns can be observed in renal stone formers by different countries: high meat/low dairy in Italy, moderate meat $\&$ cheese/low fruit \& vegetables in Greece, Bulgaria and Turkey, high meat/low vegetables (or fruit) in Romania and Serbia.

\section{REFERENCES}

1. Trinchieri A. Epidemiology of urolithiasis. Arch Ital Urol Androl. 1996; 68:203-250.

2. Trinchieri A, Coppi F, Montanari E, et al Increase in the prevalence of symptomatic urinary tract stones during the last ten years. Eur Urol. 2000; 37:23-25.

3. Akinci M. Esen T, Tellaloglu S. Urinary stone disease in Turkey: an updated epidemiological study. Eur Urol. 1991; 20:200-203.

4. Stamatiou KN, Karanasiou VI, Lacroix RE, et al. Prevalence of urolithiasis in rural Thebes, Greece Rural and Remote Health. 2006; 6:610.

5. Atanassova SS, Panchev PK. Kidney stones in a southeast European population from Bulgaria Clin Chem Lab Med. 2013; 51:e227-229.

6. Hesse A, Brandle E, Wilbert D, et al. Study on the prevalence and incidence of urolithiasis in Germany comparing the years 1979 vs 2000. Eur Urol. 2003; 44:709-713.

7. Scott R. Prevalence of calcified upper urinary tract stone disease in a random population survey. Report of a combined study of general practitioners and hospital staff. Br J Urol. 1987; 59:111-117. 
8. Martínez-González MA, Salas-Salvadó J, Estruch R, et al. PREDIMED INVESTIGATORS. Benefits of the Mediterranean Diet: Insights From the PREDIMED Study. Prog Cardiovasc Dis. 2015; 58:50-60.

9. Schwingshackl L, Hoffmann G. Does a Mediterranean-Type Diet Reduce Cancer Risk? Curr Nutr Rep. 2016; 5:9-17.

10. Scales CD Jr, Curtis LH, Norris RD, et al. Changing gender prevalence of stone disease. J Urol. 2007; 177:979-82.

11. Strope SA, Wolf JS, Jr, Hollenbeck BK. Changes in gender distribution of urinary stone disease. Urology. 2010; 75:543-6.
12. Trinchieri A, Ostini F, Nespoli R, et al. A prospective study of recurrence rate and risk factors for recurrence after a first renal stone. J Urol. 1999; 162:27-30.

13. Curhan GC, Willett WC, Rimm EB, Stampfer MJ. A prospective study of dietary calcium and other nutrients and the risk of symptomatic kidney stones. N Engl J Med. 1993; 328:833-8.

14. Trinchieri A, Maletta A, Lizzano R, Marchesotti F. Potential renal acid load and the risk of renal stone formation in a case-control study. Eur J Clin Nutr. 2013; 67:1077-80.

\section{Correspondence}

Andreas Karagiannis, MD

andreaskaragiannis@gmail.com

Andreas Skolarikos, MD

andskol@yahoo.com

Athanasios Papatsoris, MD

agpapatsoris@yahoo.gr

$2^{\text {nd }}$ Department of Urology, University of Athens,

Sismanoglio Hospital, Athens, Greece

Emanuel Alexandrescu, MD

manu_alexandrescu@yahoo.com

Petrisor Geavlete, MD

geavlete@gmail.com

Urological Department, Saint John Emergency Clinical Hospital

Bucharest, Romania

Dragoslav Basic, MD

basicdr@gmail.com

Aleksandar Skakic, MD

saleskaka@hotmail.com

Urological Clinic, Clinical Center Nis, Nis, Serbia

Alessandro Maletta, MD

a.maletta@ospedale.lecco.it

Alberto Trinchieri, MD

a.trinchieri@asst-lecco.it

Ospedale A.Manzoni, Urology Department, Lecco, Italy

A.Yaser Muslumanoglu, MD

ymuslumanoglu56@hotmail.com

Chief, Department of Urology, Bagcilar Training and Research Hospital

Istanbul, Turkey

Kremena Petkova, MD

dr_petkova@yahoo.com

Department of Urology and Nephrology, Military Medical Academy

Sofia, Bulgaria

Iliya Saltirov, MD

saltirov@yahoo.com

Skender Saidi, $M D$

skendersaidi@yahoo.com

Sotir Stavridis, MD

stavridis.sotir@gmail.com

University Clinic for Urology, University Clinical Centre "Mother

Theresa", Skopje, FYR Macedonia

Kemal Sarica, MD

Chief, Department of Urology

saricakemal@gmail.com

Dr. Lutfi Kirdar Kartal Research and Training Hospital, Istanbul, Turkey

Omer Yilmaz, MD

dr.omeryilmaz@yahoo.com

Department of Urology, GATA Haydarpasa Research and Teaching

Hospital, Istanbul, Turkey 